\title{
Microwave spectroscopy of the Mars atmosphere
}

\author{
D. O. Muhleman and R. T. Clancy
}

\begin{abstract}
A study of the use of millimeter-wavelength spectral transitions to investigate the atmosphere of Mars is presented. In the model experiments investigated it is assumed that a spectrometer in the frequency range from 100 to $260 \mathrm{GHz}$ looks into a modest-sized telescope of from 30 to $50 \mathrm{~cm}$ aperture from a near-Mars orbit. The molecules $\mathrm{H}_{2} \mathrm{O}, \mathrm{CO}, \mathrm{O}_{2}, \mathrm{O}_{3}$, and $\mathrm{H}_{2} \mathrm{O}_{2}$ all have intense spectral lines in the Mars atmosphere in this frequency range and in addition are all very important in understanding the water cycle, the photochemistry, and the circularization in that atmosphere. It is shown that the altitude and the zonal distribution of $\mathrm{H}_{2} \mathrm{O}$ can be mapped even in atmospheric columns as dry as 0.25 precipital $\mu \mathrm{m}$. Ozone can be mapped over the entire planet, independent of solar-lighting conditions, dust loading, or clouds in the atmosphere, because millimeter waves are insensitive to any particles that can be suspended in the Mars atmosphere. Because the signal-receiving techniques use superheterodyne devices and narrow spectral lines, zonal and meridional winds can be measured at altitudes above $10 \mathrm{~km}$ with a precision approaching approximately $3 \mathrm{~m} / \mathrm{s}$ by the use of Doppler shifts. Temperature-pressure profiles can be measured to altitudes of $100 \mathrm{~km}$ by the use of CO lines in the limb-sounding mode. ๑ 1995 Optical Society of America.
\end{abstract}

\section{Introduction}

The exploration of Mars remains a high priority in solar system investigations and, indeed, in human thought. The Mars Surveyor mission of the U.S. and the Mars mission of Russia are major advances in this program, and many more missions to Mars are certain to follow. Martian science is rapidly expanding, parallel to the geology, geophysics, and atmospheric sciences of the Earth. Consequently, many of the important questions of Earth science translate directly to Mars science, resulting in the need for highly accurate, quantitative experiments of a synoptic nature. A few such experiments were carried out on the two Viking lander sites and from the long-lived Viking orbiters. Although new landers undoubtedly will go to the Mars surface in the not too distant future, truly synoptic measurements can best be done from polar orbit around Mars. Synoptic measurements require instruments that will function continuously under all conditions of solar lighting and heat-

D. O. Muhleman is with the Division of Geological and Planetary Sciences, California Institute of Technology, Pasadena, California 91125. R. T. Clancy is with the Laboratory for Astrophysics and Space Physics, University of Colorado, Boulder, Colorado 80309001.

Received 11 May 1993; revised manuscript received 11 May 1993. 0003-6935/95/276067-14\$06.00/0.

(C) 1995 Optical Society of America. ing within the full range of the atmospheric winds and the dust and ice aerosol loadings. In this paper we present the analysis and design for such a class of experiments involving microwave spectroscopy and radiometry in the frequency range from approximately 100 to $300 \mathrm{GHz}(\lambda=3$ to $1 \mathrm{~mm})$. Higherfrequency systems can certainly be proposed and may have unique capabilities, but the technology for the above frequency range is available and proven, particularly with the Microwave Limb Sounder on the Upper Atmosphere Research Satellite currently orbiting the Earth.

Infrared spectroscopy has been quite successful and important in the observational study of the Mars atmosphere, both from spacecraft (Mariner 9 IRIS (infrared interferometer spectrometer), Viking IRTM (infrared thermal mapper), and MAWD (Martian atmospheric water detection) and from Earth-based instruments. Nevertheless, there exist large-scale atmospheric phenomena of fundamental interest that are not easily observed by the use of IR spectroscopy, because of large aerosol opacities in the $6-15-\mu \mathrm{m}$ wavelength region. Continuum IR opacities exceed unity in the nadir during global dust-storm and polarhood conditions and, hence, seriously degrade retrievals of atmospheric water vapor and temperature during periods of particular scientific interest. The transfer of radiation is affected by aerosols through absorption, emission, and scattering if the particle sizes are, roughly, larger than $1 / 10$ of the wave- 
length, rather independent of the optical properties of the particles. Because the largest-size particles that can be even transiently supported by the Martian atmosphere must be less than $100 \mu \mathrm{m}$ (e.g., ice crystals), experiments in which wavelengths longer than $1 \mathrm{~mm}$ are used are immune to all the aerosols.

The atmosphere of Mars is composed of $95.5 \% \mathrm{CO}_{2}$ and $2.7 \% \mathrm{~N}_{2}$, and the remainder consists of trace gases, including $\mathrm{Ar}, \mathrm{CO}, \mathrm{H}_{2} \mathrm{O}, \mathrm{O}_{2}$, and $\mathrm{O}_{3}$ (e.g., Owen et $a l .{ }^{1}$. Although the photochemical balance of the Mars atmosphere is not completely understood, it seems clear that the predominantly $\mathrm{CO}_{2}$ atmosphere is stable against photodissociation through vertical transport and chemical reactions involving $\mathrm{CO}, \mathrm{OH}$, $\mathrm{H}_{2} \mathrm{O}, \mathrm{O}_{2}$, and possibly $\mathrm{H}_{2} \mathrm{O}_{2}$ (see Refs. 2 and 3). An even more uncertain issue is the response of this photochemical-eddy diffusive balance among $\mathrm{CO}_{2}$, $\mathrm{CO}$, and $\mathrm{O}_{2}$ to seasonal variations in the $\mathrm{CO}_{2}$ partial pressure. Approximately $20 \%$ of the $\mathrm{CO}_{2}$ is condensed out of the atmosphere as frost during the pressure cycle, and $\mathrm{CO}$ and $\mathrm{O}_{2}$ remain in the vapor state. During this seasonal cycle, water vapor with a yearly average abundance of 10 precipital $\mu \mathrm{m}$ (pr. $\mu \mathrm{m})$ must be shuttled between the polar regions by a system of zonal and meridional winds and has its own vapor-ice thermodynamic cycle. ${ }^{4-6}$

A large and important subset of molecular species in the Mars atmosphere exhibits very strong transitions in the microwave. In particular, microwave sounding provides substantially greater sensitivities to $\mathrm{CO}, \mathrm{H}_{2} \mathrm{O}, \mathrm{O}_{3}, \mathrm{O}_{2}$, and $\mathrm{H}_{2} \mathrm{O}_{2}$ compared with IR sounding techniques. Furthermore, local thermodynamic equilibrium (LTE) applies to much higher altitudes (lower pressures) for microwave frequencies. This permits the derivation of atmospheric temperatures (see Section 3) from microwave CO spectra to altitudes above $100 \mathrm{~km}$ on Mars, roughly $50 \mathrm{~km}$ above where non-LTE effects become important at IR frequencies.

An important adjunct to the atmospheric chemistry is the planet's meteorology, driven by strong seasonal effects related to the large Martian rotational rate, an obliquity of $24^{\circ}$, and an appreciably eccentric orbit. The first-order effects of the global meteorology are the modulation of the total atmospheric pressure by \pm 1.5 mbars as $\mathrm{CO}_{2}$ frost caps wax and wane on the polar regions during northern and southern winters $\mathrm{s}^{4,7}$ and a robust atmospheric-circulation system. The latter has not been measured, nor is it likely to be measured during the Mars Surveyor mission, but zonal and meridional winds have been inferred from atmospheric-state data by Conrath et $a l .{ }^{8}$ and Conrath, ${ }^{9}$ and from circulation model calculations by Pollack et al. ${ }^{10}$ We believe that the direct measurement of this wind system is a high priority for future Mars missions, such as the Aeronomy Observer. Atmospheric winds can be sensed by measurement of the Doppler shifts of molecular lines due to the motion of the spacecraft with respect to the line-forming region in the atmosphere. For example, the $\mathrm{CO}$ line at $230 \mathrm{GHz}$ will be shifted by 8
$\mathrm{kHz}$ for a $10-\mathrm{m} / \mathrm{s}$ wind. Microwave spectroscopy offers a virtually unlimited spectral resolution for the accurate determination of such Doppler shifts (see Section 2).

All the phenomena discussed above are understood, or at least modeled, to the first order, but we believe that a deep understanding of the Martian aeronomy and meteorology requires much more detailed observations of the atmospheric state, chemical composition, and abundances as a function of season, latitude and altitude, wind system structure, and the details of the $\mathrm{H}_{2} \mathrm{O}$ distribution, state, and circulation. The obliquity and the spin rate of Mars are similar to those of the Earth, but with vastly different reservoirs of water. How do the circulation patterns differ on these two bodies? Although important progress will be made with the experiments on the Mars Surveyor mission (especially on the questions of the volatile budget on the planet's surface), we believe that all the questions we have raised will be addressed more rigorously with the proposed Mars Aeronomy Observer mission (or its equivalent) and several other Mars opportunities. In particular, our understanding of the atmospheric chemistry and dynamics can be greatly advanced with an experiment in which microwave spectroscopic techniques are used to measure synoptically all the major species involved in the photochemical cycles, e.g., $\mathrm{CO}, \mathrm{O}_{2}, \mathrm{O}_{3}, \mathrm{H}_{2} \mathrm{O}$, except for $\mathrm{CO}_{2}$, which can be studied with a very simple IR system. It is reasonable to expect that the detailed behavior of $\mathrm{CO}_{2}$ throughout a Martian year will be well measured by the IR sounding experiment on the Mars Surveyor mission. ${ }^{11}$

\section{Microwave Spectroscopy}

Microwave spectroscopy in the frequency range from 100 to $300 \mathrm{GHz}$ is a mature field with highly developed systems that can be made lightweight and reliable by the use of all-solid-state components. All the molecules discussed above have intense molecular transition lines in this frequency range: $\mathrm{CO}$ at 115.3 and 230.6, $\mathrm{H}_{2} \mathrm{O}$ at 183.3, $\mathrm{O}_{2}$ at 119 , and $\mathrm{O}_{3}$ at 231 and $235.7 \mathrm{GHz}$; see Table 1 for a complete list of important species. Although sufficiently strong transitions of $\mathrm{OH}$ are not available in any frequency range for Mars applications, appropriate transitions be-

Table 1. Microwave Transitions for Mars Molecular Species ${ }^{a}$

\begin{tabular}{llc}
\hline Molecule & $\begin{array}{c}\text { Wavelength } \\
(\mathrm{mm})\end{array}$ & $\begin{array}{c}\text { Surface } \\
\text { Volume Mixing Ratio }^{b}\end{array}$ \\
\hline${ }^{12} \mathrm{C}{ }^{16} \mathrm{O}$ & $1.310,2.602$ & $2 \times 10^{-3}$ \\
${ }^{13} \mathrm{C}{ }^{16} \mathrm{O}$ & $1.361,2.722$ & $2 \times 10^{-5}$ \\
${ }^{12} \mathrm{C}{ }^{18} \mathrm{O}$ & $1.366,2.733$ & $4 \times 10^{-6}$ \\
${ }^{16} \mathrm{O}^{16} \mathrm{O}$ & 2.526 & $1 \times 10^{-3}$ \\
${ }^{16} \mathrm{O}^{18} \mathrm{O}$ & $1.282,2.52$ & $2 \times 10^{-6}$ \\
$\mathrm{O}_{3}$ & $1.255,1.273$ & $2 \times 10^{-8}$ \\
$\mathrm{H}_{2} \mathrm{O}$ & 1.637 & $3 \times 10^{-4}$ \\
$\mathrm{H}_{2} \mathrm{O}_{2}$ & 1.305 & $2 \times 10^{-8}$ \\
$\mathrm{HO}_{2}$ & many lines & $5 \times 10^{-10}$ \\
\hline
\end{tabular}

${ }^{a}$ Strongest line in wavelengths of 1 to $3 \mathrm{~mm}$.

${ }^{b}$ Representative values, e.g., $\mathrm{H}_{2} \mathrm{O}$ and $\mathrm{O}_{3}$ highly variable. 
tween 230 and $235 \mathrm{GHz}$ are available for the related and important $\mathrm{H}_{2} \mathrm{O}_{2}$ hydroxyl.

The quantities one retrieves from these transitions are somewhat dependent on the viewing conditions (nadir versus limb sounding) and the abundance and variability of the particular molecular species. The $\mathrm{CO}$ and $\mathrm{O}_{2}$ molecules are believed to be well mixed vertically and horizontally because of their large photochemical lifetimes (>2 years, e.g., Ref. 2). Hence the $\mathrm{CO}$ and $\mathrm{O}_{2}$ microwave opacities permit temperature sounding of the Mars atmosphere, either in limb viewing, which provides temperature versus altitude profiles with good vertical resolution $(\sim 5 \mathrm{~km})$ and poorer horizontal resolution $(\sim 200 \mathrm{~km})$, or in nadir viewing (for the more optically thick CO line only), which provides temperature versus pressure profiles with poorer vertical resolution $(\sim 10 \mathrm{~km})$ and high horizontal resolution $(10 \mathrm{~km})$. If an independent measure of the vertical temperature profile is made available (such as from a radio occultation), the $\mathrm{CO}$ and $\mathrm{O}_{2}$ mixing profiles may be independently derived from their respective spectral lines.

The scarcer $\mathrm{O}_{3}$ and $\mathrm{H}_{2} \mathrm{O}_{2}$ species may be best studied from limb sounding, although $\mathrm{O}_{3}$ column abundances can be determined with nadir viewing when it exceeds $\sim 10 \mu \mathrm{m}$ atm (such as during winter conditions ${ }^{12}$ ). The $\mathrm{O}_{3}$ abundance on Mars is known to be highly variable, and freezing out of $\mathrm{H}_{2} \mathrm{O}_{2}$ has been suggested to lead to variability of atmospheric $\mathrm{H}_{2} \mathrm{O}_{2} \cdot{ }^{13}$

The $\mathrm{H}_{2} \mathrm{O}$ transition at $183.3 \mathrm{GHz}$ is extremely important for the study of Mars. Under average Martian conditions of $10 \mathrm{pr}$. $\mu \mathrm{m}$ the normal opacity of the atmosphere in the line center is approximately 20 . We argue below that the measurement accuracy of the column of $\mathrm{H}_{2} \mathrm{O}$ would be approximately $10 \%$ for regions and epochs on Mars where the abundance is greater than approximately $0.1 \mathrm{pr}$. $\mu \mathrm{m}$. Under conditions in which the column abundance is greater than 1 pr. $\mu \mathrm{m}$, our analysis shows that mixing-ratio retrievals accurate to approximately $\pm 5 \%$ can be achieved.

The frequencies that we are considering are sufficiently high that excellent spatial resolution can be achieved by the use of a telescope with a relatively small aperture size, as illustrated in Fig. 1. For example, at a spacecraft height of $300 \mathrm{~km}$ above the Martian surface, the HWHM beam for the $\mathrm{H}_{2} \mathrm{O}$ line $(\lambda=1.64 \mathrm{~mm})$ when a $33-\mathrm{cm}$ aperture is used would be $7.2 \mathrm{~km}$ on the limb tangent point and $2.3 \mathrm{~km}$ on the surface. Thus the resolution for limb sounding in the $\mathrm{H}_{2} \mathrm{O}$ line with a small telescope would be approximately half an atmosphere scale height. Subscale height resolutions would be achieved with a $50-\mathrm{cm}$ aperture. Such a telescope mirror with sufficient rigidity and accuracy would have a mass less than 2 $\mathrm{kg}$. The selection of the limb sounding, nadir sounding, or limb-to-nadir scanning would depend on the particular mission and its priorities. Limb sounding offers advantages for measuring atmospheric winds, the detection of spectral lines of very-low-abundance

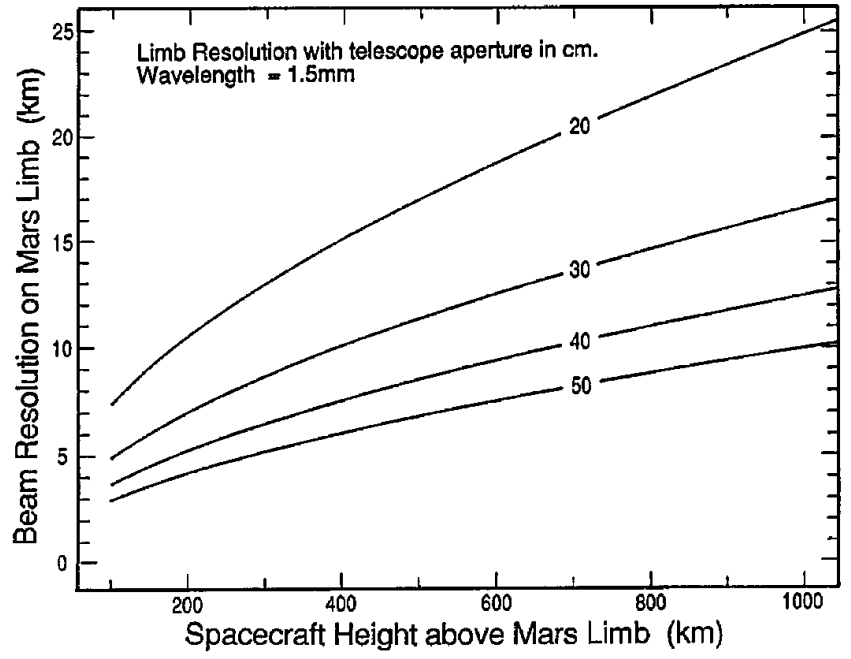

Fig. 1. Telescope beam altitude resolution when the Mars limb is viewed as a function of the spacecraft altitude for apertures of 20 , 30,40 , and $50 \mathrm{~cm}$.

species, and the measurement of the atmospheric temperature versus pressure profile when high vertical resolution is needed. Nadir viewing is simpler, yields temperature versus pressure profiles to at least a scale-height resolution, and directly measures column abundances without assumptions of lateral homogeneity in the atmosphere. A much smaller aperture can be used for nadir sounding because the beam size affects only the measurement of lateral variations in meteorology, e.g., resolving a weather front while flying over it. Resolution in the direction of the motion of the spacecraft is smeared proportionally to the integration time in any case; consequently, a nadir-viewing resolution of approximately $10 \mathrm{~km}$ is instrumentally practical and sufficient for meteorological mapping for integration times of the order of 1 s. Microwave spectroscopic techniques for the investigation of Mars' atmosphere have the following advantages, particularly with respect to UV, visible, and IR techniques:

1. Instrument weighting functions are completely immune to the aerosol loading in the atmosphere and, as such, always probe into the lowest scale height of the atmosphere.

2. Intense transitions exist in the major photochemical molecules of the atmosphere, $\mathrm{H}_{2} \mathrm{O}, \mathrm{CO}, \mathrm{O}_{2}$, and $\mathrm{O}_{3}$, as well as for important trace species such as $\mathrm{H}_{2} \mathrm{O}_{2}$. Note that $\mathrm{HO}_{x}$ species $\left(\mathrm{OH}, \mathrm{HO}_{2}, \mathrm{H}_{2} \mathrm{O}_{2}\right)$ are not easily observed at UV, visible, or IR wavelengths.

3. Instruments are highly reliable because they can be built with all-solid-state devices and no moving parts, except for beam-pointing mirrors. Examples are spacecraft communications systems and the Microwave Limb Sounder instrument on the UARS.

4. Instruments are low mass and power: approximately $2 \mathrm{~kg}$ and $5 \mathrm{~W}$ per frequency band, with an overhead less than $20 \mathrm{~kg}$ and $10 \mathrm{~W}$, including the telescope. 
5. Instruments at wavelengths near $1 \mathrm{~mm}$ can operate in the limb-sounding mode with half-scale resolution or the nadir mode with one-scale-height resolution with a $30-\mathrm{cm}$ aperture.

\section{Objectives and Capabilities}

Microwave spectroscopy is able to address major questions concerning the Mars atmosphere and its interaction with the surface. In this section we discuss a range of unanswered scientific questions and present a realistic error analysis of projected microwave measurements designed to answer these questions.

\section{A. Water Vapor}

There already exists a large body of information on Mars atmospheric water, largely from the Viking IR radiance measurements of MAWD ${ }^{5}$ and ground-based observations (e.g., Barker ${ }^{14}$ ). The MAWD observations indicate that surface reservoirs in polar ice ${ }^{5,15}$ and the regolith ${ }^{6,16}$ lead to large seasonal and global variations of atmospheric water vapor. The Earthbased observations indicate that interannual variations are also likely. ${ }^{14,17}$ Primary disadvantages of these observations are that they provided limited information on the vertical distribution of water and did not provide information during polar night and in times of global dust storms and polar hood formation. Limited spatial $\left(\sim 5^{\circ}\right.$ latitudinal $)$ and temporal (approximately monthly for a given region) resolutions also limit the MAWD data set for examining interesting regions such as the advancing and retreating seasonal caps (in addition to obscuration by the polar hood).

Observations during the polar night, seasonal cap growth, and global dust storms and the altitude distribution of water vapor are in fact primary pieces of information for understanding the seasonal and global budget of $\mathrm{H}_{2} \mathrm{O}$ and surface-atmosphere interactions (e.g., Jakosky ${ }^{18}$ ). Microwave spectroscopy will accurately define atmospheric profiles of water vapor with much increased temporal and latitudinal resolution during the polar night and global dust storms and, in addition, provide complimentary measurements of atmospheric temperature-pressure profiles, regolith density, seasonal ice-cap growth, and winds (hence, meridional transport). This combined data set will greatly facilitate modeling the global cycle of water in the atmosphere, the regolith, and the seasonal and the residual polar caps.

The combinations of atmospheric temperature, water vapor, and wind measurements may be used to address the following questions: (a) Is the water abundance generally well mixed below $\sim 20 \mathrm{~km}$ as suggested by MAWD? ${ }^{19}$ (b) Is the water vapor above $\sim 20 \mathrm{~km}$ controlled by temperature because of vapor equilibrium? Previous observations do not adequately define the vertical distribution of water vapor. (c) To what extent does the lower atmospheric temperature influence the local water column? (d) Do diurnal temperature variations in the lower scale height and the related observations of morning fog (e.g., Pollack et al., ${ }^{20}$ Flasar and Goody ${ }^{21}$ ) lead to measurable changes in atmospheric water vapor in the lower scale height? (e) Do significant amounts of water condense out of the polar night? (f) What is the specific saturation state of water vapor in the polar hood as a function of time? (g) What are the distinctions between the two hemispheres and their polar regions with regard to water vapor? (h) Given the abundance of the airborne dust load measured with MO instruments, what effects do global dust storms have on the global distribution of water?

\section{B. Nadir Sounding of Water Vapor}

A nadir-sounding channel is designed to produce high spatial and moderate vertical resolution maps of the atmospheric $\mathrm{H}_{2} \mathrm{O}$ mixing ratio in addition to very sensitive determinations of the total column abundances, i.e., $0.1 \mathrm{pr}$. $\mu \mathrm{m}$. The specific vertical resolution and accuracy for these measurements will vary depending on the particular distribution and column of water vapor at each point. The instrument can be designed to alternately determine the atmospheric temperature-pressure profile from measurements of the $\mathrm{CO}$ transition(s) and to sense the $\mathrm{H}_{2} \mathrm{O}$ vapor with a duty cycle as short as $20 \mathrm{~s}$. The determination of the $\mathrm{H}_{2} \mathrm{O}$ distributions from $\mathrm{IR}$ or microwave $\mathrm{H}_{2} \mathrm{O}$ spectra requires accurate temperature-pressure profiles which are not compromised by aerosol loading effects on the measurements during the very times of interest. Microwave temperature-pressure sounding is discussed in detail in Subsection 3.D. At a spacecraft altitude of $300 \mathrm{~km}$ or higher, the ground track speed is $3 \mathrm{~km} / \mathrm{s}$ or less. Thus a polar-orbiting vehicle would yield a latitudinal spatial resolution of better than 30 $\mathrm{km}$ and a comparable longitudinal resolution (depending on the antenna size).

The visibilities of microwave water lines in the Mars atmosphere are illustrated in Figs. 2-4 for the rather ad hoc altitude distributions selected for this purpose. Figure 2 shows two synthetic $183-\mathrm{GHz}$ lines (plus realistic system noise) for a midlatitude temperature profile, assuming that $B=1$ and $10 \mathrm{pr}$. $\mu \mathrm{m}$ of $\mathrm{H}_{2} \mathrm{O}$ to saturation followed by saturation conditions. Because the gas is relatively cold over a warm surface the lines appear in absorption. Figure 3 illustrates the sensitivity of nadir $\mathrm{H}_{2} \mathrm{O}$ spectra to the altitudes distribution of water vapor. All four spectra incorporate a midlatitude temperature profile and a water column of $10 \mathrm{pr}$. $\mu \mathrm{m}$, which is uniformly distributed in 5-, 15-, 25-, and 80-km layers above the surface. These lines appear in emission in the wings and are self-absorbed in the line center. Figure 4 illustrates a situation that may occur over a winter pole, where one would expect all the water vapor to have condensed out, and with a surface temperature at the $\mathrm{CO}_{2}$ sublimation temperature near $150 \mathrm{~K}$. It is possible that strong upper-atmospheric winds would blow a small amount of $\mathrm{H}_{2} \mathrm{O}$ vapor over these regions. Figure 4 illustrates the cases in which $1 \mathrm{pr}$. $\mu \mathrm{m}$ of water vapor is distributed with a constant 


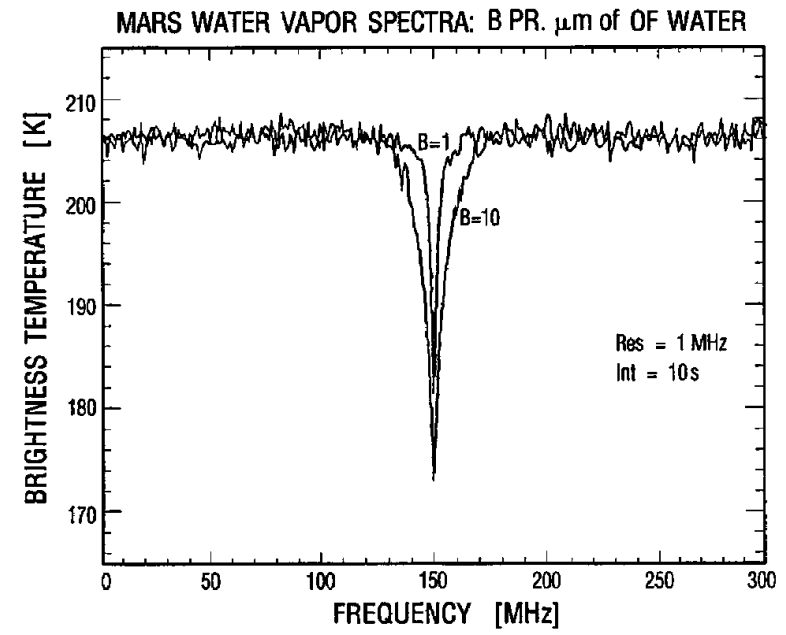

Fig. 2. Nadir-viewing synthetic $183-\mathrm{GHz}$ spectra for $\mathrm{H}_{2} \mathrm{O}$ vapor column abundances of 1 and $10 \mathrm{pr}$. $\mu \mathrm{m}$ for the Martian midlatitudes. The spectra have been corrupted by realistic measurement noise in a 10-s integration (INT). Res, resolution.

mixing ratio for altitudes above 25,10 , and $0 \mathrm{~km}$. The lines appear completely in emission as the adopted temperature profile is characterized by warmer temperatures above a cold surface. A Viking polar radio occultation temperature versus pressure profile was used to calculate these $\mathrm{H}_{2} \mathrm{O}$ spectra (see Fig. 11, below). All the $\mathrm{H}_{2} \mathrm{O}$ spectra shown in Figs. 2-4 have distinct line shapes and depths that contain information on the vertical distribution of $\mathrm{H}_{2} \mathrm{O}$ abundances as well as the total column abundances.

We present three cases for $\mathrm{H}_{2} \mathrm{O}$ mixing-ratio retrievals based on nadir observations from a microwave spectrometer water channel. These cases are presented to represent the accuracy and the vertical resolution of the $\mathrm{H}_{2} \mathrm{O}$ profile retrievals for nominal conditions $(10 \mathrm{pr}$. $\mu \mathrm{m}$ of water at summer midlatitudes), high-abundance conditions (40 pr. $\mu \mathrm{m})$, and low-abundance conditions $(0.25 \mathrm{pr}$. $\mu \mathrm{m}$ of water at the winter pole).

The nominal midlatitude case is shown in Fig. 5. The input profile (designated by the plus signs) is a

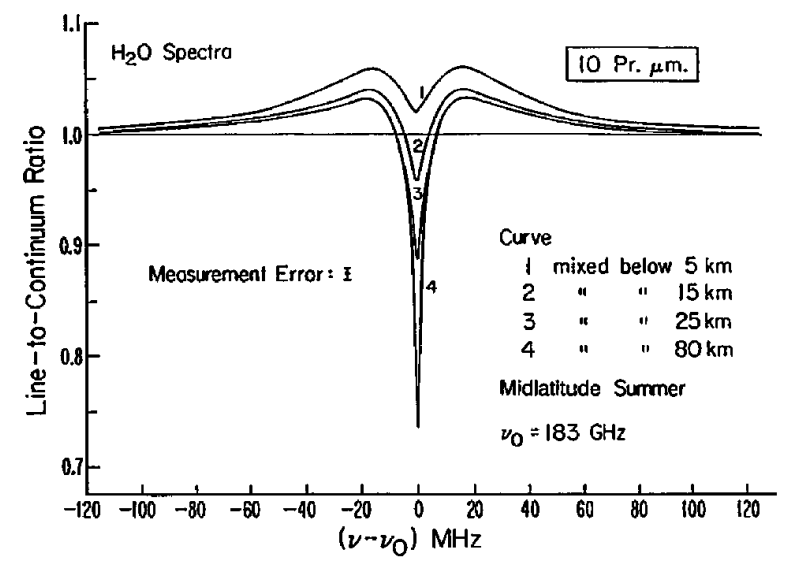

Fig. 3. Synthetic nadir-viewing lines for uniformly mixed $\mathrm{H}_{2} \mathrm{O}$ below altitudes of $5,15,25$, and $80 \mathrm{~km}$. In each case the column abundance is $10 \mathrm{pr} . \mu \mathrm{m}$.

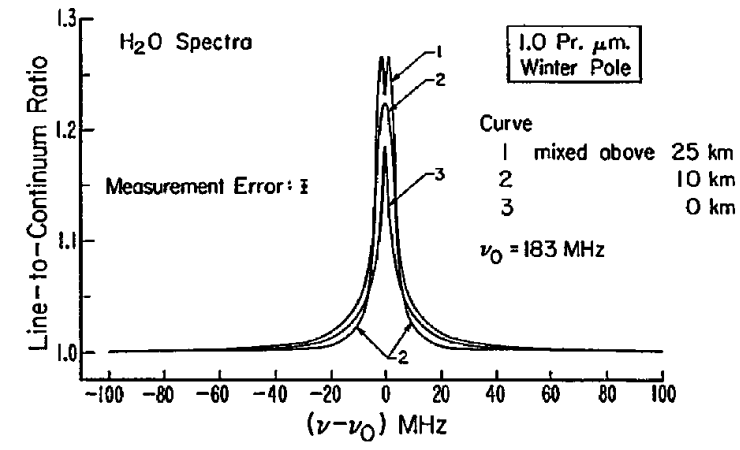

Fig. 4. Synthetic nadir-viewing lines for uniformly mixed $\mathrm{H}_{2} \mathrm{O}$ above altitudes of 0,10 , and $25 \mathrm{~km}$ over the cold winter pole. Total abundance is always $1.0 \mathrm{pr} . \mu \mathrm{m}$.

vapor-equilibrium profile of water vapor in the pressure range of $\sim 0.04-4$ mbars. Above and below this region, the $\mathrm{H}_{2} \mathrm{O}$ mixing ratio is set to $1.75 \times 10^{-4}$, such that the integrated water column equals $10 \mathrm{pr}$. $\mu \mathrm{m}$. The dashed curves are six separate inversions for the $\mathrm{H}_{2} \mathrm{O}$ mixing profile, derived from a synthetic $\mathrm{H}_{2} \mathrm{O}$ spectrum with added Monte Carlo Gaussian noise. Noise equivalent to that expected from the temperature-pressure profile is used in the inversions. The temperature-pressure profile was adapted from the Viking 2 descent profile.

The inverted profiles reproduced three basic features from the input profile: (1) a constant mixing ratio below $\sim 1$ mbar at which the total water available is not sufficient for saturation; (2) a region between $\sim 1$ and 0.3 mbars at which saturation occurs; and (3) above $\sim 0.3$ mbars at which $\mathrm{H}_{2} \mathrm{O}$ again becomes undersaturated. The match of input and derived profiles for this case is likely to be representative of the $\mathrm{H}_{2} \mathrm{O}$ profile-retrieval accuracy for nadir observations, although we may still increase the information return from the spectra with further development of the inversion techniques. (The inver-

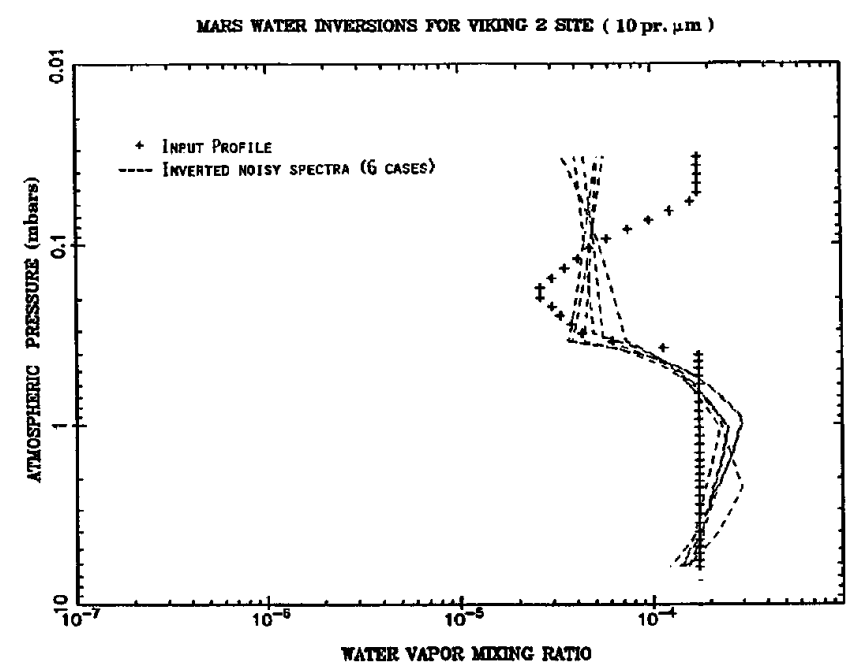

Fig. 5. Water vapor retrievals (dashed curves) from synthetic spectra plus noise for uniformly mixed profiles to saturation with total water of $10 \mathrm{pr} . \mu \mathrm{m}$. A midlatitude, summer temperaturepressure profile is assumed, along with nadir sounding. 
sion techniques used here evolve from constrained, least-mean-squared inversions, somewhat similar to Twomey-Chahine techniques.) Vertical integration of the derived mixing profiles yields a column of $10.8 \pm 1 \mathrm{pr}$. $\mu \mathrm{m}$, which is to be compared with the input of $10 \mathrm{pr} . \mu \mathrm{m}$. As with the accuracy of the vertical distribution, we may expect to do better with further development of the inversion technique, e.g., the overshoots in the retrieved profiles are a consequence of the use of linear segments in the estimated profiles.

Our second case assumes the same Viking 2 temperature-pressure profiles (see Fig. 10, below) as the first case, with 40 pr. $\mu \mathrm{m}$ of water in the atmosphere. This large amount of water permits better definition of the minimum in the water abundance in Fig. 6 at $\sim 0.2$ mbars. The increase in water for both the input profile and the solution profiles between 0.1 and 0.003 mbars is due to a temperature maximum in the temperature-pressure profile; hence the vapor approaches undersaturation in this region (see Fig. 8, below). The retrieved column abundance for the solutions is $40 \pm 3 \mathrm{pr}$. $\mu \mathrm{m}$. We show a far more difficult case in Fig. 7, in which the plus signs indicate a plausible $\mathrm{H}_{2} \mathrm{O}$ mixing profile over the winter pole. Saturation below $\sim 1$ mbar leads to very low $\mathrm{H}_{2} \mathrm{O}$ vapor in the lower atmosphere and a low column abundance $(0.25 \mathrm{pr} . \mu \mathrm{m})$. The upper boundary mixing of $2 \times 10^{-5}$ was assumed to produce this column. The solution profiles (dashed curves) were again inverted from a synthetic spectrum with noise added. The temperature-pressure profile plus noise (see Fig. 11, below) was modeled after Mariner 9 IRIS observations of the northern winter pole. ${ }^{8}$ The inverted profiles yield very good agreement with the input profile above 1 mbar. They reproduce the falloff of water vapor below 1 mbar, although the inversion has noticeable difficulty in matching the sharpness and altitude of the falloff. This particular case, in which there is a sharp discontinuity in the lower scale height of the atmosphere, represents a worst-case test for nadir-viewing microwave water vapor retrievals.

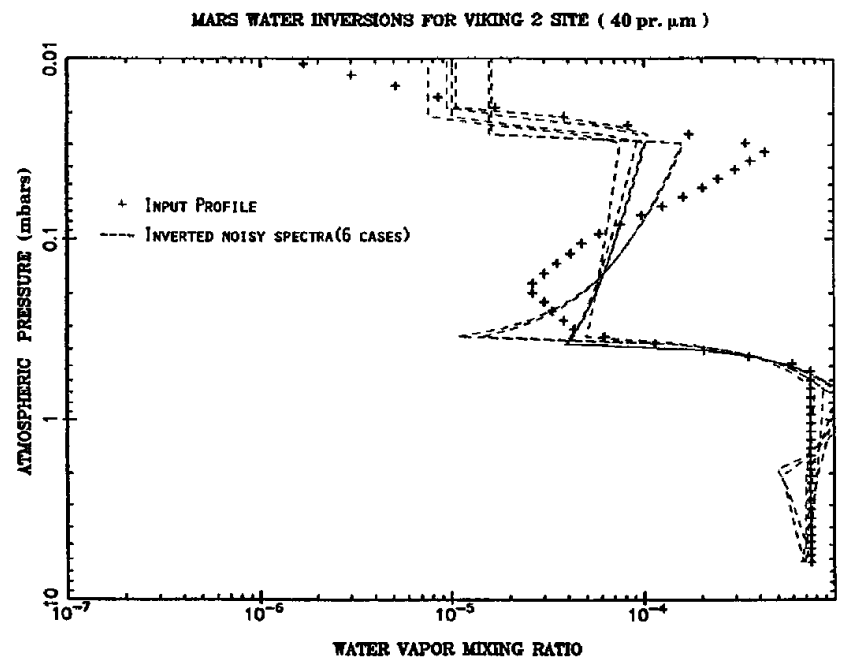

Fig. 6. Same as for Fig. 5 but for a total water abundance of 40 pr. $\mu \mathrm{m}$.

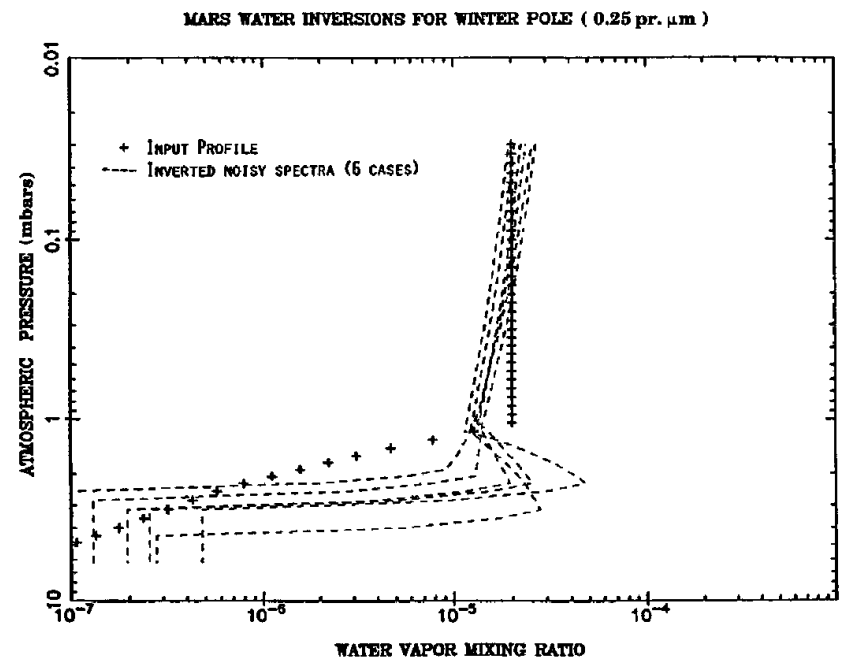

Fig. 7. Same as for Fig. 5 but for a total water abundance of 0.25 pr. $\mu \mathrm{m}$ over the winter pole. For $B T(K)$, a $1-\mathrm{MHz}$ resolution is assumed.

The solutions shown in Fig. 7 produce a water column of $0.5 \pm 0.3 \mathrm{pr}$. $\mu \mathrm{m}$. The inversion algorithm requires further study to improve solutions for this type of water vapor profile.

Microwave nadir sounding in the $183-\mathrm{GHz}$ line will generally retrieve a $10 \%$ accuracy in the water column abundance with sensitivity for columns lower than $0.1 \mathrm{pr}$. $\mu \mathrm{m}$, depending on the specific altitude distribution of the water. Nadir observations also exhibit reduced sensitivity for regions in which the atmosphere is isothermal and close in temperature to the brightness temperature of the surface.

\section{Limb Sounding of Water Vapor}

As a general rule, limb sounding improves both the sensitivity and the altitude resolution of atmospheric measurements at the expense of horizontal resolution. For observations of Mars atmospheric water vapor, the advantages of limb sounding are quite significant. Figure 8 presents limb-weighting functions for the $183-\mathrm{GHz}$ water line for the nominal midlatitude water mixing profile in Fig. 5. Unnormalized weighting functions at representative altitudes of $0-80 \mathrm{~km}$ are shown for a $1-\mathrm{MHz}$ channel placed at selected frequency offsets from the $183-\mathrm{GHz}$ line center. These frequency offsets were chosen to optimize slant limb opacities for maximum altitude resolution and intensity of the weighting functions. The optimum frequency offsets $\left(v-v_{0}\right)$ and the model water mixing ratios $\left(\mathrm{H}_{2} \mathrm{O}\right)$ are indicated at each tangent altitude. In practice the full range of frequency offsets would be observed at each tangent altitude. The model brightness temperatures provided in Fig. 8 indicate the estimated signal strength measured at the given tangent altitude and frequency offset, assuming a $1-\mathrm{MHz}$ channel width. An upper-limit estimate of signal-noise limitations in the accuracy of derived water mixing profiles can be made when a $\pm 1-K$ measurement error in brightness temperature is assumed. Hence, the resulting signal-to-noise er- 


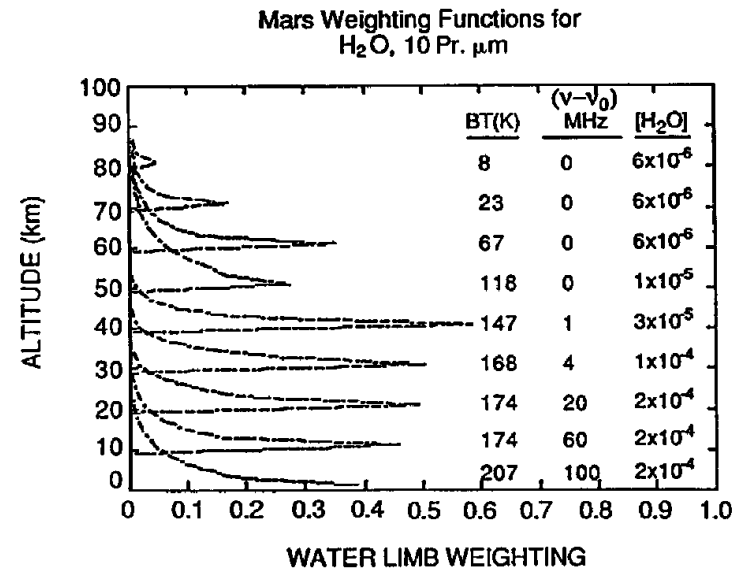

Fig. 8. Limb-sounding weighting functions for 10 pr. $\mu \mathrm{m}$ of $\mathrm{H}_{2} \mathrm{O}$ uniformly mixed to saturation. The brightness temperature $B T(K)$ at $\left(v-v_{0}\right) \mathrm{MHz}$ from the line center is shown in tabular form. Also shown is the assumed $\mathrm{H}_{2} \mathrm{O}$ mixing ratio $\left.\left(\mathrm{H}_{2} \mathrm{O}\right]\right)$ as a function of altitude. In each case, it is assumed that an infinitely narrow beam is pointed at the limb at the altitude shown.

rors in the water mixing profile are of the order of a few percent below $50 \mathrm{~km}$ altitude and $10 \%$ near 100 $\mathrm{km}$ altitude.

Limb-weighting functions for the much-reduced water vapor abundances of the winter pole are presented in Fig. 9. Accurate water vapor profiles could be retrieved between 10 and $80 \mathrm{~km}$ altitude. A lower limit of $\sim 10^{-7}$ for the water mixing ratio would be determined for altitudes below $\sim 10 \mathrm{~km}$.

Water vapor limb-sounding observations for the Mars atmosphere offer significant improvements over nadir observations. Four important improvements are listed below:

1. The vertical resolution is limited primarily by the diffraction beam of the antenna. The inherent limb-viewing vertical resolution is $\sim 2 \mathrm{~km}$, i.e., the half-power width of the curves shown in Fig. 8, which is approximately half the diffraction-limited limb resolution for a 50-cm telescope at a frequency of 183

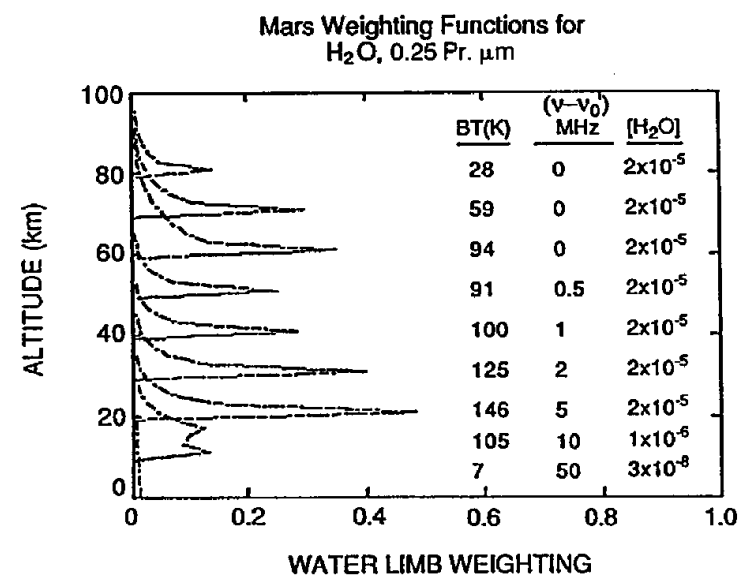

Fig. 9. Same as for Fig. 8 but for a total water abundance of 0.25 pr. $\mu \mathrm{m}$ over the winter pole. For $B T(K)$, a $1-\mathrm{MHz}$ resolution is assumed.
GHz. Note, however, that the horizontal resolution for limb sounding $(\sim 200 \mathrm{~km})$ is significantly degraded relative to the nadir-viewing horizontal resolution $(\sim 30 \mathrm{~km})$.

2. The sensitivity of water vapor limb observations is ideal for Mars observations. Accurate definition $( \pm 10 \%)$ of water vapor mixing profiles up to $50 \mathrm{~km}$ should be provided for any conceivable water vapor profile in the Mars atmosphere.

3 . The water emission is always viewed against the 3-K background of space for limb viewing, versus the $\sim 200-\mathrm{K}$ background of Mars for nadir viewing. Hence the sensitivity of limb viewing is not subject to the variable contrast between atmospheric and surface temperatures, as is the case for nadir viewing.

4. Water vapor determinations from limb observations are also less sensitive to uncertainties in the atmospheric-temperature profile.

\section{Temperature-Pressure Sounding}

The temperature and pressure of a planetary atmosphere can be determined from the measurements of a calibrated microwave spectral line of a well-mixed molecular species, such as the $\mathrm{CO}(1-0)$ line, by sensing the blackbody emission shape across the line's spectrum. Temperature information is contained in the brightness temperatures themselves, and pressure information can be extracted from the line shape through the pressure-broadening mechanism. The limb- and the nadir-sounding cases are different manifestations of the same phenomenon. Limb sounding with a $30-50-\mathrm{cm}$ telescope actually resolves the emission in an altitude range delimited by the beam, one half-scale height being easily achievable on Mars. In spectral regions in which the line is optically thin, the brightness temperature and the linewidth directly yield the physical temperature and the pressure, respectively, after a small correction for the contribution of the (known) layers just above the ray tangent point on the limb.

Nadir sounding is somewhat more complex because the instrument, at a given frequency channel in the spectral line, senses emission from the planet's surface, emission from the atmosphere, and self-absorption of these emissions because of the colder layers of the atmosphere above. Nevertheless we show below that such data are readily invertible in terms of temperature (and pressure) versus altitude but are limited to scale-height resolution.

Primary scientific goals of microwave temperaturepressure sounding include (1) seasonal and meteorological variations in atmospheric temperatures, (2) inferred geostrophic winds that can be compared with direct Doppler observations, (3) meridional heat transport to poles both from the measured latitudinal gradient in atmospheric temperatures and from direct meridional wind measurements, (4) the relationship of atmospheric temperatures to water vapor measurements and condensate measurements from other spacecraft instruments, (5) the relation of ground temperatures from IR and microwave surface 
brightness temperatures to the lower atmospheric temperatures, (6) the relation of atmospheric temperatures and the seasonal ice cover as determined from other surface-property measurements, (7) differences in atmospheric and surface temperatures for the north and the south poles of Mars, (8) measuring atmospheric temperatures cold enough to form $\mathrm{CO}_{2}$ clouds (such as at the southern winter pole), (9) the radiative-balance effects of global dust storms on the atmospheric-temperature profile up to a $60-\mathrm{km}$ altitude, and (10) disturbances. Limb-sounding measurements have sufficient resolution to detect wave structures in the atmosphere, such as gravity waves.

Microwave temperature retrievals are characterized by three important strengths in the millimeter wavelength sounding technique. First, the observations are independent of the state of the atmosphere. Unambiguous temperature-pressure profiles can be obtained on the day and the night sides, for very cold atmospheric conditions, during intense formation of atmospheric condensates, and during the most intense dust storm conditions. These are, of course, conditions for which accurate knowledge of the temperature-pressure profile are most interesting. Second, nadir sounding provides high spatial resolution for observing such phenomena as sharp temperature gradients across weather fronts, atmospheric temperatures across the retreating or growing seasonal caps, the local variation of atmospheric temperatures at winter poles, and atmospheric-heating effects of localized dust storms. Finally, non-LTE effects do not affect microwave temperature retrievals to atmospheric pressures well below 0.0001 mbars. Hence temperature profiles can be returned to the $60-\mathrm{km}$ altitude level from nadir sounding and to the $100-\mathrm{km}$ level from limb sounding. Correction for non-LTE effects, particularly with limb sounding, can be complex and must compromise the accuracy of retrievals.

\section{E. Nadir Sounding for Temperature-Pressure Profiles}

A CO 1.3-mm channel would provide maps of the temperature-pressure profile with high spatial and moderate vertical resolutions with nadir viewing. (Limb sounding in this channel with a $30-\mathrm{cm}$ telescope aperture achieves a beam size on the limb of $6 \mathrm{~km}$ from an altitude of $300 \mathrm{~km}$. We discuss this case below.) Horizontal resolution is that for water vapor maps. The temperature-pressure profiles will extend from the surface to $\sim 0.01$ mbar, with scaleheight resolution. An average temperature in the region of 0.01-0.001 mbars is also retrieved. Error bars on the temperature-pressure profiles are independent of atmospheric or surface temperatures and would be $\pm 2^{\circ}$ (because of absolute calibration limitations of the instrument) for individual measurements based on this study.

We show temperature-pressure inversions for two cases for the Mars atmosphere. In Fig. 10 we present six separate temperature-pressure inversions (dashed curves) of synthetic $1.3-\mathrm{mm}$ (CO) spectra (with noise). The input profile, denoted by plus

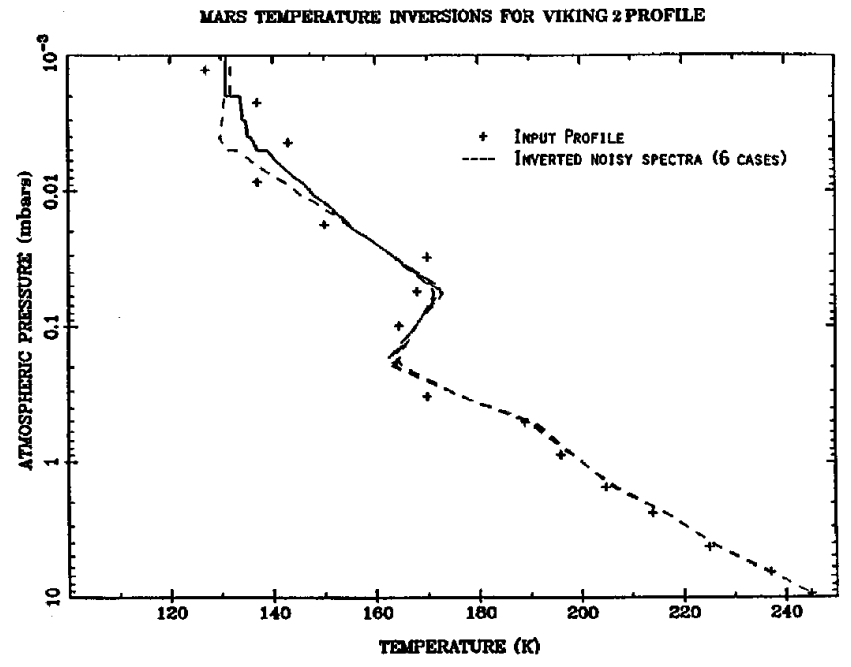

Fig. 10. Temperature-pressure retrievals (dashed curve) from synthetic spectra corrupted by noise; nadir viewing. The input temperature-pressure profile $(+)$ is the Viking 2 measurement.

signs, is taken from the descent observations of the Viking 2 Lander. Three important results may be obtained from examination of Fig. 10: (1) the inversions accurately reproduce the input solution below $\sim 0.4$ mbars, $(2)$ the temperature wave structure between 0.4 and 0.002 mbars is retrieved by the solution from the $\sim 20-\mathrm{km}$ wavelength of this structure. The inversion finds a smooth mean (solid curve) through the temperature structure above $\sim 0.002$ mbars because of the shorter wavelength structure of temperature in this region, (3) noise in the spectrum does not introduce significant noise in the temperature inversions. The \pm 2 -K error is primarily an uncertainty in the absolute calibration of the instrument.

Figure 11 illustrates retrieval for an inverted temperature-pressure profile over the cold winter pole. We have constructed a model profile (plus signs) on the basis of Mariner 9 IRIS observations from Conrath

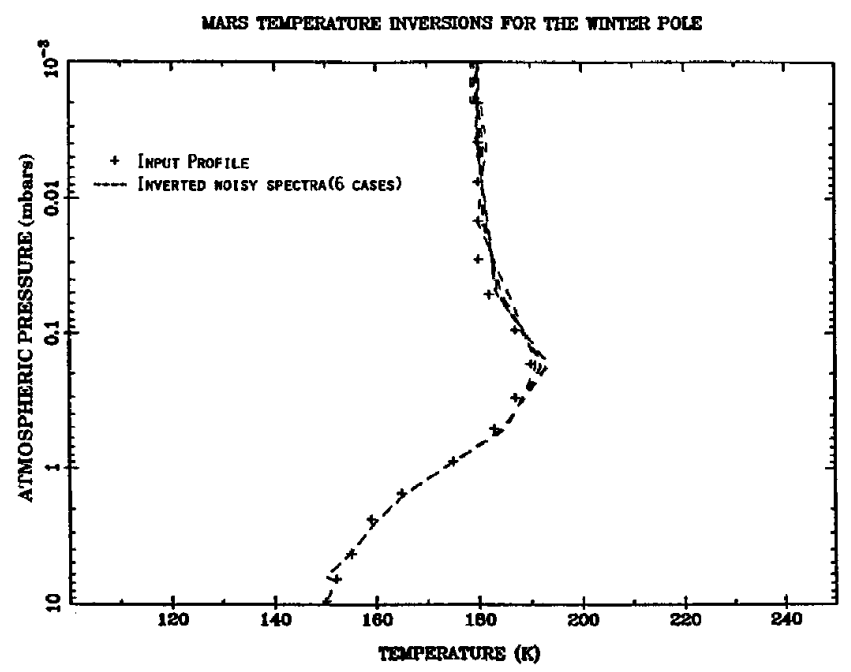

Fig. 11. Same as for Fig. 10 but for the winter pole. The input temperature-pressure profile is from a radio occultation inversion. 
et al. ${ }^{8}$ The synthetic solutions (dashed curves) reproduce the input profiles, including a maximum in temperature at $\sim 0.2$ mbars, quite accurately. These two examples are typical of all the temperaturepressure profiles we have synthesized. The temperature-sounding data inversions allow us to obtain temperature-pressure profiles with temperatures accurate to $\pm 2 \mathrm{~K}$ under all imaginable Mars atmospheric conditions. A number of questions remain to be examined. We believe that we can determine the mean global surface pressure to approximately \pm 0.25 mbars by averaging spectra over several days. The diurnal variation in the Mars surface temperature would be easily detected, and such spectra would also be somewhat sensitive to the diurnal variations in the atmosphere in the lower scale height.

\section{F. Limb Sounding for Temperature-Pressure Retrieval}

Improvements in temperature-pressure sounding gained from limb viewing are less significant than for water vapor retrievals. The primary advantage gained in limb sounding for atmospheric temperatures is the increased vertical resolution of the observations. This is particularly important for the study of vertical wave structures. Sensitivity increases over nadir viewing are significant primarily for increasing the altitude range of temperature sounding to above $100 \mathrm{~km}$. For altitudes below $\sim 60 \mathrm{~km}$, CO opacities in limb and nadir sounding are always sufficient for accurate temperature-pressure sounding. Furthermore, variations in the contrast of surface and atmospheric temperatures do not significantly affect limb temperature-pressure sounding, except perhaps for the lowest scale height. These distinctions between water vapor and temperature observations in the nadir follow from the distinction in $\mathrm{H}_{2} \mathrm{O}$ and $\mathrm{CO}$ opacities in the Mars atmosphere. $\mathrm{CO}$ is well mixed in the Mars atmosphere, because of its long photochemical lifetime. Hence variability of $\mathrm{CO}$ opacities is driven by moderate seasonal and latitudinal variations in Mars atmospheric pressures. Atmospheric $\mathrm{H}_{2} \mathrm{O}$ mixing ratios are variable by several orders of magnitude because of the extreme atmospheric-temperature dependence of $\mathrm{H}_{2} \mathrm{O}$ condensation. As a result, water vapor weighting functions are extremely variable in time and position on Mars. Optically thin conditions, which may apply to the entire $\mathrm{H}_{2} \mathrm{O}$ spectrum, can lead to sensitivity of the entire derived $\mathrm{H}_{2} \mathrm{O}$ mixing profile with Mars surface brightness temperatures. Temperature derivations from the CO line are sensitive to Mars' surface temperatures only when temperatures in the lowest scale height are being retrieved, because this is the only region in which one is required to use the optically thin portion of the line.

Midlatitude weighting functions for limb sounding in the $\mathrm{CO} J=2-1(230.538-\mathrm{GHz})$ line are shown in Fig. 12. The unnormalized weighting functions, brightness temperature, optimum frequency offsets $\left(v-v_{0}\right)$, and CO mixing profile are presented as they are for water vapor in Figs. 8 and 9. Half-scaleheight temperature profiles with a \pm 2 - $\mathrm{K}$ accuracy

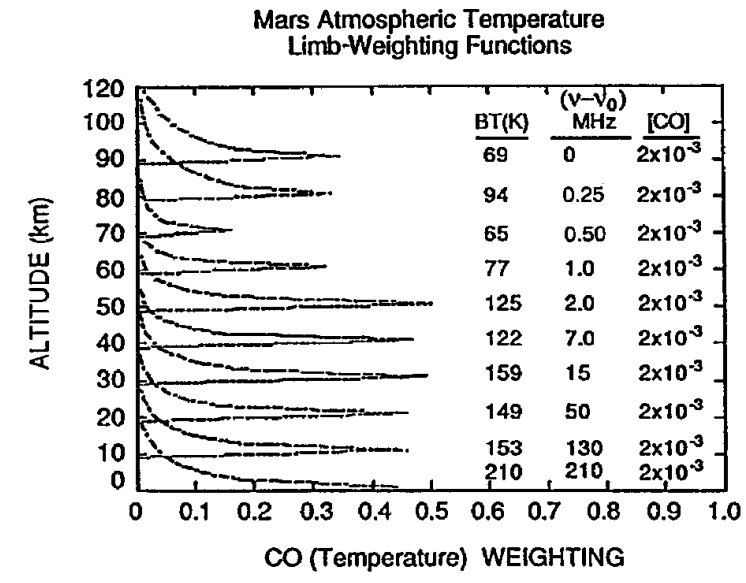

Fig. 12. Same as for Fig. 8 but the weighting functions are for the $\mathrm{CO}(2-1)$ line used for temperature-pressure inversions. For $B T(K)$, a $1-\mathrm{MHz}$ resolution is assumed.

could be retrieved between 0 and $70 \mathrm{~km}$ altitude. Temperature sounding with a $\pm 5-\mathrm{K}$ accuracy could be extended to $110-130 \mathrm{~km}$ altitude.

\section{G. $\mathrm{O}_{3}, \mathrm{O}_{2}, \mathrm{H}_{2} \mathrm{O}_{2}$ Measurements}

The photochemistry of the Mars atmosphere is remarkably similar to the photochemistry in the terrestrial stratosphere-mesosphere. In both cases photolysis of trace amounts of atmospheric water vapor supplies $\mathrm{HO}_{x}$ radicals that act as catalytic recombination agents for $\mathrm{O}_{2}$ and $\mathrm{CO}_{2}$. Important photochemical species include $\mathrm{CO}, \mathrm{O}, \mathrm{O}_{3}, \mathrm{OH}, \mathrm{HO}_{2}$, and $\mathrm{H}_{2} \mathrm{O}_{2}$. The stability of the Mars $\mathrm{CO}_{2}$ atmosphere requires that the photolysis products of $\mathrm{CO}_{2}\left(\mathrm{O}, \mathrm{O}_{2}, \mathrm{CO}\right)$ be efficiently recombined into $\mathrm{CO}_{2}$. There exist significantly different photochemical cycles for $\mathrm{CO}_{2}$ recombination, all of which involve odd hydrogen species $(\mathrm{H}$, $\mathrm{OH}, \mathrm{HO}_{2}$; e.g., McElroy and Donahue, ${ }^{2}$ Parkinson and Hunten, ${ }^{22}$ Kong and McElroy, ${ }^{23}$ ). A major unresolved question is the degree to which rapid vertical mixing or high abundances of odd hydrogen account for the relatively low abundance of CO observed in the Mars atmosphere.

The oxygen species that result from $\mathrm{CO}_{2}$ photolysis $\left(\mathrm{O}, \mathrm{O}_{2}, \mathrm{O}_{3}\right)$ are predicted to be anticorrelated with the abundances of the odd hydrogen species. Spatially and temporally variable column abundances for $\mathrm{O}_{3}$ in the Martian atmosphere have been noted from ground-based observations ${ }^{24}$ and Mariner 9 UVS observations. ${ }^{12}$ The observed $\mathrm{O}_{3}$ column is found to be anticorrelated with atmospheric temperatures, which are in turn presumed to be correlated with atmospheric water vapor abundances, because of water condensate formation in the Martian atmosphere. ${ }^{12}$ The much-longer-lived $\mathrm{O}_{2}$ molecule has been observed from ground-based observations ${ }^{25-27}$ and is expected to exhibit insignificant or much weaker annual variations, as predicted for $\mathrm{CO} .{ }^{13}$ Hunten ${ }^{13}$ has suggested that seasonal variations in $\mathrm{CO}$ may be driven by seasonally dependent condensation of $\mathrm{H}_{2} \mathrm{O}_{2}$ from the Mars atmosphere. Lower 
$\mathrm{H}_{2} \mathrm{O}_{2}$ abundances reduce the recombination rates for $\mathrm{CO}$, leading to increased $\mathrm{O}_{2}$ and $\mathrm{CO}$ abundances.

Microwave spectroscopic observations can provide accurate observations of $\mathrm{O}_{2}, \mathrm{O}_{3}$, and $\mathrm{H}_{2} \mathrm{O}_{2}$. The combination of these observations with data from microwave $\mathrm{CO}, \mathrm{H}_{2} \mathrm{O}$, and temperature sounding would provide a fairly complete study of the photochemistry of the Mars atmospheres, including the condensation of $\mathrm{H}_{2} \mathrm{O}$ and $\mathrm{H}_{2} \mathrm{O}_{2}$.

$\mathrm{H}$. Nadir Sounding of $\mathrm{O}_{3}, \mathrm{O}_{2}$, and $\mathrm{H}_{2} \mathrm{O}_{2}$

Microwave emissions from $\mathrm{O}_{3}, \mathrm{O}_{2}$, and $\mathrm{H}_{2} \mathrm{O}_{2}$ are much weaker than are those for $\mathrm{CO}$ and $\mathrm{H}_{2} \mathrm{O}$ because of the lower atmospheric abundances for $\mathrm{O}_{3}$ and $\mathrm{H}_{2} \mathrm{O}_{2}$ and a much smaller absorption coefficient for the $\mathrm{O}_{2}$ magnetic dipole transition. Figure 13 presents a synthetic nadir spectrum for an enhanced $\mathrm{O}_{3}$ column abundance $(40 \mu \mathrm{m} \mathrm{atm})$ over the cold winter pole. Such increased $\mathrm{O}_{3}$ column abundances during nighttime polar winter conditions, which are not observable by the use of UV scattered-light techniques, are observable with microwave techniques.

Winter and midlatitude $\mathrm{O}_{2}$ emissions for a constant $\mathrm{O}_{2}$ mixing ratio of $1.3 \times 10^{-3}$ are presented in Fig. 14 . The $\mathrm{O}_{2}$ spectrum appears in absorption at midlatitudes, where atmospheric temperatures above $\sim 10$ $\mathrm{km}$ altitude exceed the surface brightness temperature. Because of the weak absorptions of $\mathrm{O}_{2}$ and $\mathrm{O}_{3}$, it is not practical to obtain vertical mixing profiles of these species from nadir observations. Relatively accurate $(\sim 10 \%)$ column abundances for $\mathrm{O}_{2}$ and $\mathrm{O}_{3}$ (at maximum abundances) could be retrieved from such observations. Observations of $\mathrm{H}_{2} \mathrm{O}_{2}$ in the Mars atmosphere require limb viewing.

I. Limb Sounding of $\mathrm{O}_{3}, \mathrm{O}_{2}$, and $\mathrm{H}_{2} \mathrm{O}_{2}$

Increased sensitivities from limb sounding are particularly advantageous for studies of trace species. Limbweighting functions and brightness temperatures for the 231.3-GHz $\mathrm{O}_{3}$ transition are presented in Fig. 15

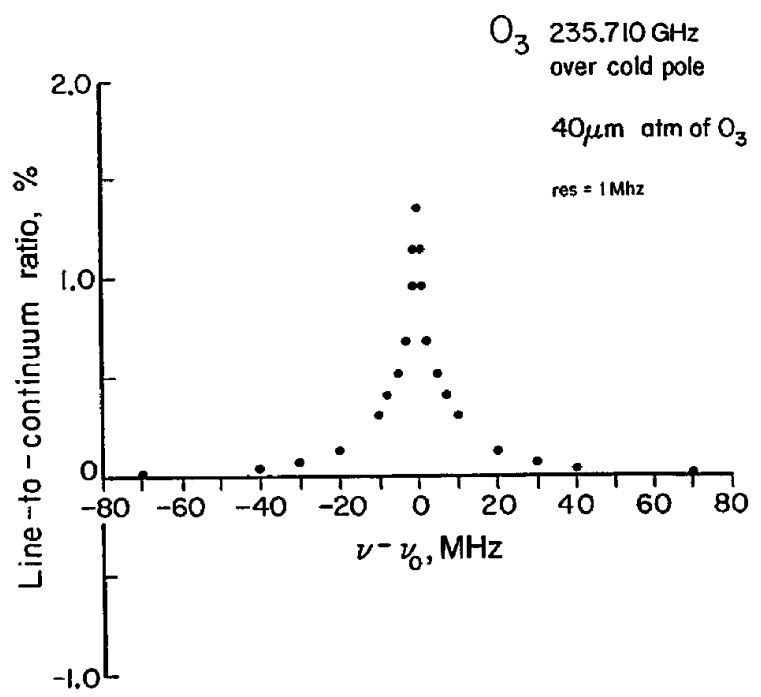

Fig. 13. Synthetic $\mathrm{O}_{3}$ spectral line $(235.7 \mathrm{GHz})$ over the winter pole, as obtained with nadir viewing.

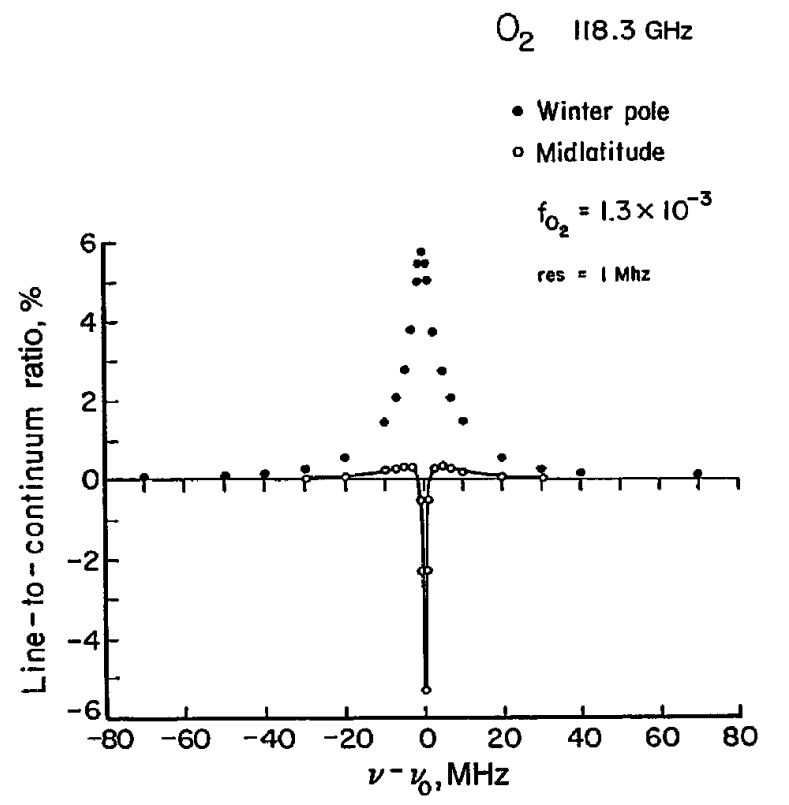

Fig. 14. Synthetic $\mathrm{O}_{2}$ spectral lines $(118.3 \mathrm{GHz})$ over the winter pole (emission) and midlatitudes (absorption).

for an atmospheric column abundance of $2.7 \mu \mathrm{m}$ atm. The adopted $\mathrm{O}_{3}$ profile (see Fig. 15) is based on the photochemical model of Kong and McElroy ${ }^{23}$ and reflects globally averaged column abundances for $\mathrm{O}_{3}$. Minimum ozone column abundances at equatorial latitudes are apparently in the range of $1-2 \mu \mathrm{m}$ atm. ${ }^{24}$ It is expected that the ozone vertical profile presented in Fig. 15 could be determined with an accuracy of $\sim 10 \%$ below an altitude of $30 \mathrm{~km}$, given modest system-noise temperatures $(\sim 1000 \mathrm{~K})$ and relatively short time integrations per altitude $\left(\begin{array}{ll}\sim & \mathbf{s}\end{array}\right)$. Determination of the ozone mixing profile above 30 $\mathrm{km}$ would require longer integrations.

$\mathrm{Limb}$-weighting functions for the $118-\mathrm{GHz} \mathrm{O}_{2}$ transition are presented in Fig. 16, under the assumption of a constant $\mathrm{O}_{2}$ mixing ratio of $1.3 \times 10^{-3}$ and a nominal midlatitude temperature-pressure profile. $\mathrm{O}_{2}$ mixing profiles of $\sim \pm 5 \%$ accuracy are achievable

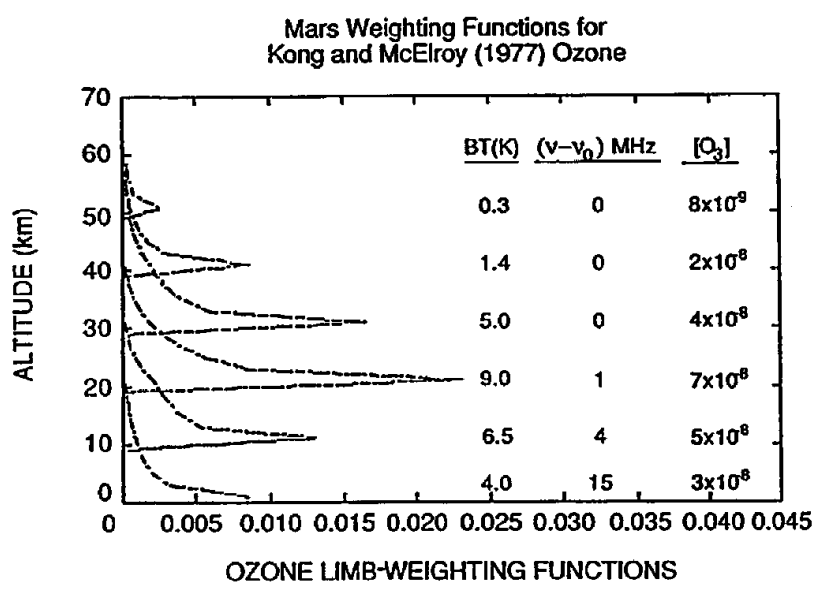

Fig. 15. Same as for Fig. 8 but for $\mathrm{O}_{3}(231.3 \mathrm{GHz})$. For $B T(K)$, a $1-\mathrm{MHz}$ resolution is assumed. 


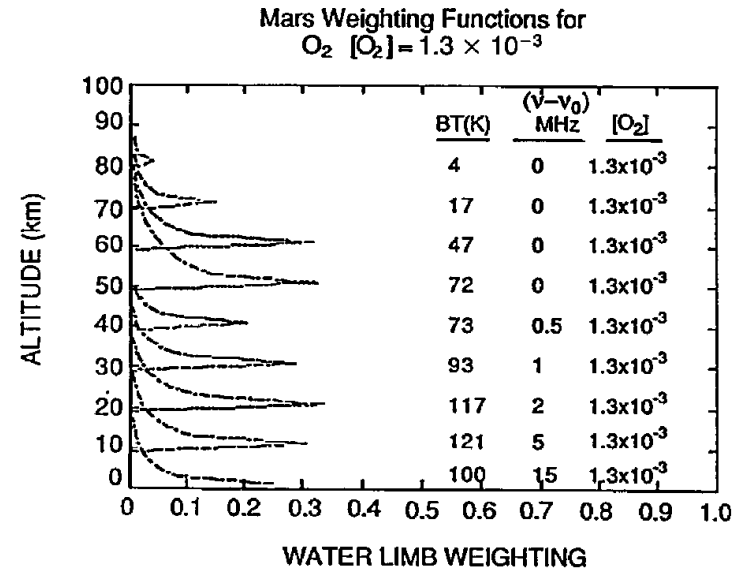

Fig. 16. Same as for Fig. 8 but for $\mathrm{O}_{2}(118.3 \mathrm{GHz})$.

from such limb-viewing observations. As for the case of $\mathrm{H}_{2} \mathrm{O}$, limb sounding for $\mathrm{O}_{3}$ and $\mathrm{O}_{2}$ leads to much-reduced sensitivity to uncertainties in the atmospheric-temperature profile.

Based on the $\mathrm{H}_{2} \mathrm{O}_{2}$ mixing profiles of Kong and McElroy, ${ }^{23}$ we have calculated $\mathrm{H}_{2} \mathrm{O}_{2}$ limb-weighting functions (at $229.8 \mathrm{GHz}$, which is not shown in Fig. 16) of approximately one half the strength presented for $\mathrm{O}_{3}$ in Fig. 15. Hence we project the capability of measuring $\mathrm{H}_{2} \mathrm{O}_{2}$ profiles below the $30-\mathrm{km}$ altitude with $\sim 20 \%$ accuracy. Determination of $\mathrm{H}_{2} \mathrm{O}_{2}$ mixing profiles above the $30-\mathrm{km}$ altitude would require longer integrations, which are certainly feasible.

\section{J. Wind Measurements}

The determination of the wind fields on Mars as a function of latitude, season, and topography is a major goal of Mars research. The only direct measurements of winds are those at the Mars surface on the Viking Landers. Significant theoretical investigations in the form of general circulation models have been made by Leovy and Mintz ${ }^{28}$ and Pollack et al. ${ }^{10}$ IRIS measurements on Mariner 9 and radio occultation measurements have been used to compute geostrophic wind fields by Conrath ${ }^{9}$ and Pollack et al. ${ }^{10}$ These models predict zonal winds from 10 to $200 \mathrm{~m} / \mathrm{s}$ over the altitude range from 10 to $40 \mathrm{~km}$. A major driving mechanism for the general circulation is the condensation and sublimation of $\mathrm{CO}_{2}$ at winter poles during the solstices. Atmospheric dust can be an important radiative source of the upper atmospheric winds as shown by Haberle et al. ${ }^{29}$ Meridional transport of water and dust during these periods may be a key process in the growth of polar dust and condensate deposits (Pollack et al. $\left.{ }^{20}\right)$. Equator-to-pole meridional circulation of $5-10 \mathrm{~m} / \mathrm{s}$ has been predicted by Pollack et al., ${ }^{10}$ which will be rather difficult to measure by any technique.

All practical models of the circulation of the atmosphere of Mars require wind measurements from the surface to altitudes of $60 \mathrm{~km}$ for their development and verification. Additionally, synoptic measurements of the wind field before and during the development of major dust storms are required for a better understanding of the impact of this meteorological phenomenon on global circulation (see Haberle et al. ${ }^{29}$.

An obvious technique for measuring the winds remotely is to use Doppler shifts of very narrow emission lines (see value below). Heterodyne receivers that use a moderately stable reference oscillator are ideal for this purpose. For a component of wind toward the spacecraft of $1 \mathrm{~m} / \mathrm{s}$, a spectral line formed in the region of the wind at $200 \mathrm{GHz}$ would be blue shifted by $667 \mathrm{~Hz}$. Thus the frequency reference for an absolute measurement of winds to this accuracy requires an oscillator-synthesizer that is accurate to approximately $300 \mathrm{kHz}$, well within the range of current technology. Although the Doppler shift that results from the motion of the spacecraft relative to the planet can be as large as $2700 \mathrm{kHz}$ for a line near $200 \mathrm{GHz}$ (and a spacecraft velocity of $4 \mathrm{~km} / \mathrm{s}$ ), the spacecraft velocity is always known to better than 1 $\mathrm{m} / \mathrm{s}$, and the effect of this phenomenon is easily corrected. A much more serious error source is the knowledge and stability of the spacecraft orientation (attitude control). If the orientation of the spacecraft and the pointing direction of the telescope are in error by an angle $\epsilon$, there will be an unwanted Doppler velocity equal to $V_{s / c} \sin \epsilon$ sensed by the instrument. For this error source to be $1 \mathrm{~m} / \mathrm{s}$ or less for $V_{s / c}=4$ $\mathrm{km} / \mathrm{s}, \epsilon$ (or a knowledge of $\epsilon$ ) must be less than 0.25 mrad or 0.9 arcmin. This is nearly an order of magnitude better than the value of $\epsilon$ expected for the Mars Surveyor spacecraft, and because it is a polar orbiter, the cross-track or zonal wind measurements would have an error of nearly $10 \mathrm{~m} / \mathrm{s}$ from this effect. Down-track wind measurements are not affected by $\epsilon$ and $V_{s / c}$. There are no wind measurements planned for the Mars Surveyor. Practical wind measurements on future spacecraft will require knowledge of the instrument pointing direction to an accuracy of $0.2-0.5 \mathrm{mrad}$, which is certainly achievable.

Remote sounding of wind velocities is best done with limb sounding. The telescope is pointed at a given point on the limb, at a specific height above the local surface. The geometry of this is illustrated in Fig. 17, in which the size of the beam is greatly

\section{Limb-Sounding Geometry}

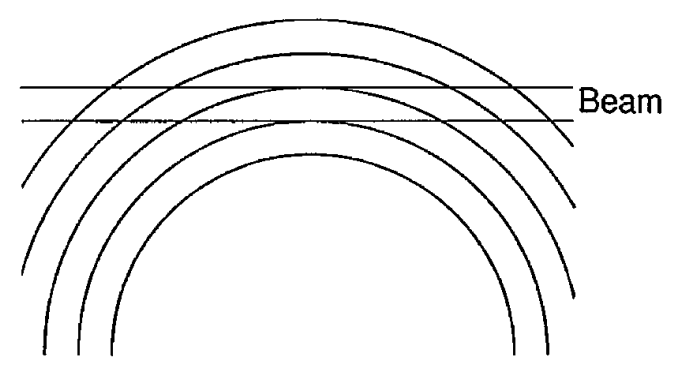

Fig. 17. Diagram of limb-sounding geometry illustrating the strong contribution from the tangent shell (determined by the beam width) relative to the shells above it. 
exaggerated relative to the radius of the planet. The aperture-size and spacecraft-altitude dependencies of limb resolution on Mars are shown in Fig. 1; values of $5-10 \mathrm{~km}$ are easily achieved for orbital heights of $300-500 \mathrm{~km}$, with aperture sizes from 30 to $40 \mathrm{~cm}$. If the beam size on the Mars limb is $10 \mathrm{~km}$, then the mean optical depth averaged over the shell in Fig. 17 is 27 times the normal optical depth of that shell, and consequently nearly all the emitted-spectral-line flux is created in the tangent shell. Contributions due to altitudes above the tangent layer become significant for tangent heights below $20 \mathrm{~km}$ but are essentially negligible above that. This can be seen in Fig. 18, in which synthetic limb spectra for the carbon 13 isotope of $\mathrm{CO}(2-1)$ are shown at $10-\mathrm{km}$ limb-height levels. The spectra for the tangent point at the surface of Mars and at $10 \mathrm{~km}$ are rather strongly self-absorbed by the atmosphere above the tangent layers. For tangent altitudes above $20 \mathrm{~km}$ the self-absorption is small, and the Doppler shift of the entire spectral line can be ascribed to the tangent shell on the limb of the width determined by the beam size. Below this level, the wind measurement of the tangent shell is increasingly corrupted by the winds in the layers in front of that shell; i.e., wind measurements below 20 $\mathrm{km}$ will exhibit correlated errors with the layers just above it.

We have performed an error analysis of microwave wind measurements with the spectra of ${ }^{13} \mathrm{CO}$, as this line is optically thin enough to minimize correlations between the layers and optically thick enough to yield accurate measurements to an altitude of $70 \mathrm{~km}$.

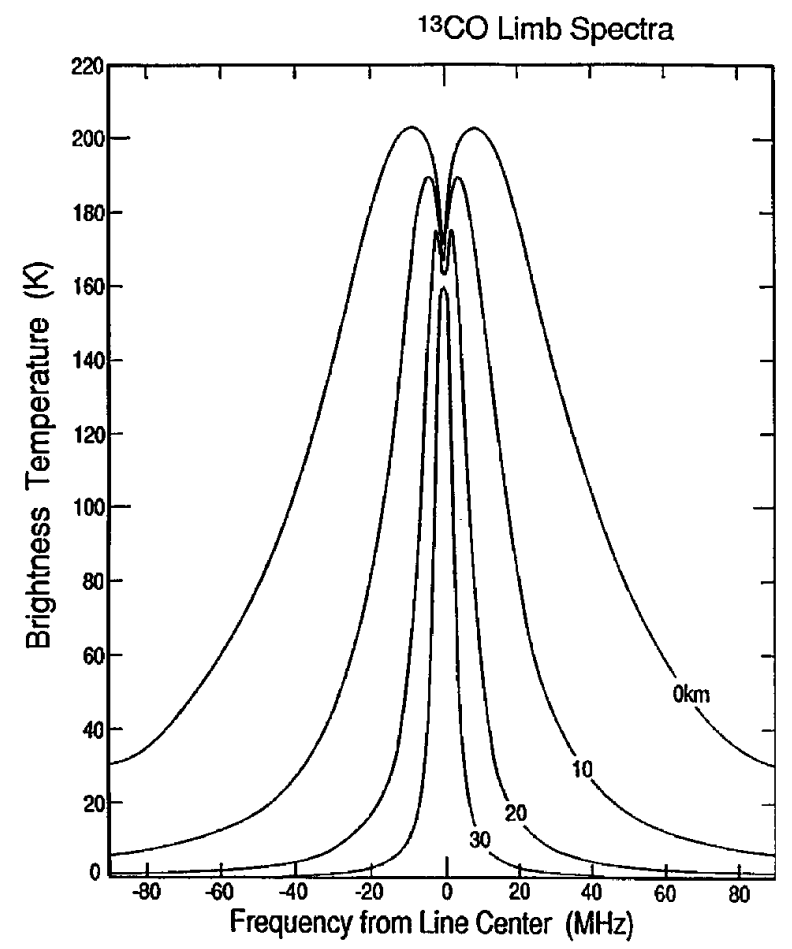

Fig. 18. Synthetic limb spectra for the isotope line ${ }^{13} \mathrm{C}^{18} \mathrm{O}$ for tangent altitudes of $0,10,20$, and $30 \mathrm{~km}$. Note the self-absorption below $20 \mathrm{~km}$ altitude.
The analysis incorporates values of $2 \times 10^{-3}$ for the mixing ratio, $\mathrm{CO} / \mathrm{CO}_{2}$, and a ${ }^{12} \mathrm{C} /{ }^{13} \mathrm{C}$ isotope ratio of 100. The optimum detection of the Doppler shift requires a spectral resolution approximately greater than the full-width at half-maximum of the limb spectra. Synthetic limb spectra are calculated with a $1-\mathrm{MHz}$ channel resolution at altitudes of 0,10 , and $20 \mathrm{~km}$ (total spectral width of $\pm 50.0 \mathrm{MHz}$ ), with a $200-\mathrm{KHz}$ resolution at altitudes of 30,40 , and $50 \mathrm{~km}$ (total spectral width of $\pm 10 \mathrm{MHZ}$ ), and with a 100 $\mathrm{KHz}$ resolution at altitudes 60 and $70 \mathrm{~km}$ (total spectral width of $\pm 4 \mathrm{MHz}$ ). Model estimates of noise errors are based on a single-sideband noise temperature of $T_{\mathrm{sy}}=1200 \mathrm{~K}$. Uncooled mixer receivers operating near $\lambda=1.0 \mathrm{~mm}$ can readily achieve such noise figures. ${ }^{30}$ For a channel width resolution res and an integration time $t$, the noise fluctuation in each channel is given by

$$
T_{\text {noise }}=\frac{2 T_{\mathrm{sy}}}{(\operatorname{res} t)^{1 / 2}}
$$

The error analysis uses an integration time $t=60 \mathrm{~s}$, the values of res listed above, and the partial derivatives of the ${ }^{13} \mathrm{CO}$ spectra with respect to the velocity of the atmosphere to estimate the standard deviations on wind measurements for the discrete limb heights listed in Table 2.

The carbon 13 isotope of $\mathrm{CO}$ was chosen for this analysis because this gas is well mixed in the Mars atmosphere, in addition to possessing optimum limb opacities. Although the results would be useful all the way to the surface of Mars, the errors are large at low altitudes, as indicated in Table 2. A second CO isotope that exhibits reduced limb opacities for improved sounding below $20 \mathrm{~km}$ is the $\mathrm{C}^{18} \mathrm{O}$ molecule (see Table 1). The use of both CO-isotope lines provides an excellent system for measuring the mean zonal and meridional winds to an accuracy of approximately $\pm 5 \mathrm{~m} / \mathrm{s}$ for 60 -s integrations over the 10 $70-\mathrm{km}$ altitude range. Such observations from a polar orbiter could produce synoptic mapping of the wind fields from the ground to $70 \mathrm{~km}$ over the entire planet.

Table 2. Covariance Analysis for Mars Wind Measurements with the ${ }^{13} \mathrm{CO}$ Spectral Line

\begin{tabular}{cccc}
\hline $\begin{array}{c}\text { Altitude } \\
(\mathrm{km})\end{array}$ & $\begin{array}{c}\text { Resolution } \\
(\mathrm{MHz})\end{array}$ & $\begin{array}{c}\text { Spectrum } \\
\text { Width }(\mathrm{MHz})\end{array}$ & $\begin{array}{c}\text { Standard Deviation } \\
\text { of Wind Estimates } \\
(\mathrm{m} / \mathrm{s})\end{array}$ \\
\hline 0 & 1.0 & \pm 50 & \pm 17 \\
10 & 1.0 & 50 & 13 \\
20 & 1.0 & 50 & 9 \\
30 & 0.2 & 10 & 3.9 \\
40 & 0.2 & 10 & 2.4 \\
50 & 0.2 & 10 & 1.7 \\
60 & 0.1 & 4 & 1.5 \\
70 & 0.1 & 4 & 3.0 \\
\hline
\end{tabular}




\section{K. Surface Emission}

When Mars is observed in the nadir mode or toward the planet's limb, a strong continuum flux from the near surface is detected. This emission is blackbody radiation generated in the Mars regolith within approximately 100 wavelengths of the surface. Experience with millimeter-wavelength emission from the Moon and less extensive Martian observations suggests that the emission phenomena are the same as those at centimeter wavelengths for the Moon and the terrestrial planets, which are well understood. The observed surface emission is essentially the integral of the local temperature distribution with depth weighted by the absorption coefficient in the soil and rock. The corresponding weighting functions decrease exponentially with depth and are characterized by microwave skin depths ranging from a few to 50 wavelengths (depending on the porosity, fine graininess, and rock count of the regolith). Consequently, millimeter-wavelength skin depths should range from roughly a few millimeters to approximately $5 \mathrm{~cm}$. Nadir observations from the polar orbit in the continuum could determine the diurnal temperature wave, which has a thermal skin depth of approximately $4 \mathrm{~cm}$. Such measurements contain important information about the density, thermal parameters, and rough composition in the upper 10-100 cm of the surface. In addition, millimeter brightness temperature measurements could determine the annual and the latitudinal variations in the mean near-surface temperatures, similar to thermal IR measurements.

If soil moisture greater than approximately $2 \%$ exists anywhere on Mars within 10-30 cm of the surface, millimeter continuum measurements will be sensitive to it. In perfectly dry soil with a density of $\sim 1 \mathrm{gm} / \mathrm{cm}^{3}$, the 1-mm weighting function is an exponential with a skin depth of approximately $10 \mathrm{~cm}$. Because the absorption coefficient for liquid water is very large at this wavelength, the presence of just a few percent of liquid water raises the microwave weighting functions very near to the surface, causing the temperature to be sensed very near the surface. One would expect the most likely presence of liquid water in the afternoon, when the subsurface temperature gradient rapidly increases toward the surface. Thus a moist region would display an anomalously high brightness temperature relative to a dry or frozen region of similar composition. We believe that this technique may be the most sensitive for the detection of near-surface liquid water by the use of remote sensing.

\section{Summary}

A detailed study of the atmosphere of Mars during the next decade would greatly benefit from remotely sensed microwave spectroscopy from a close orbit. Current technology permits the construction of microwave spectrometers capable of measuring the distribution of $\mathrm{H}_{2} \mathrm{O}, \mathrm{CO}, \mathrm{O}_{2}, \mathrm{O}_{3}, \mathrm{H}_{2} \mathrm{O}_{2}$, and their various isotopes in the atmosphere of Mars over the $0-100-\mathrm{km}$ altitude range. The observational frequency range (100 to $250 \mathrm{GHz}$ ) has several advantages over IR atmospheric sounding of Mars, including complete insensitivity to atmospheric dust, aerosols, and Martian clouds. The $183-\mathrm{GHz} \mathrm{H}_{2} \mathrm{O}$ line is an extremely sensitive $(\sim 0.1$ pr. $\mu \mathrm{m})$ indicator of atmospheric water vapor, hence it offers an excellent probe for mapping the water vapor altitude distribution as a function of longitude and latitude, seasons, and dust-loading conditions. Microwave spectroscopy is also ideal for measuring temperature-pressure profiles to altitudes above $100 \mathrm{~km}$ with $\mathrm{CO}$ spectral lines $(230 \mathrm{GHz})$. An altitude resolution of $5 \mathrm{~km}$ can be achieved in the limb-sounding mode with a telescope aperture less than $50 \mathrm{~cm}$.

Trace abundances of $\mathrm{O}_{2}, \mathrm{O}_{3}$, and $\mathrm{H}_{2} \mathrm{O}_{2}$ can also be observed at microwave frequencies $(118,231.3$, and $229.8 \mathrm{GHz}$ ) to determine fully the chemistry of the Martian atmosphere. Direct measurements of Martian winds can be made by the use of the Doppler shifts of the various spectral lines, particularly the $\mathrm{C}$ and $\mathrm{O}$ isotopes of $\mathrm{CO}$. These wind observations, complemented by coincident observations of pressuretemperature and water vapor profiles, would contribute greatly to our understanding of the atmospheric circulation and meteorology on Mars. Finally, microwave surface continuum observations provide a sensitive technique for the detection of near-surface liquid water on Mars. Such an experiment is best carried out from a polar orbiter in the altitude range from 250 to $500 \mathrm{~km}$, i.e., similar to that of the proposed Mars Aeronomy mission and the current Mars Surveyor mission.

We thank Yuk Yung and Mark Allen for numerous helpful discussions about the atmosphere of Mars. This work was supported by the NASA Planetary Instrument Development and Definition Program under contract NASW 3983.

\section{References}

1. T. Owen, K. Biemann, D. R. Rushneck, J. E. Biller, D. W. Howarth, and A. L. Lafleur, "The composition of the atmosphere at the surface of Mars," J. Geophys. Res. 82, 4635-4639 (1977).

2. M. B. McElroy and T. M. Donahue, "Stability of the Martian atmosphere," Science 177, 986-988 (1972).

3. D. M. Hunten and M. B. McElroy, "Production and the escape of hydrogen on Mars," J. Geophys. Res. 75, 5989-6001 (1970).

4. R. B. Leighton and B. C. Murray, "Behavior of carbon dioxide and other volatiles on Mars," Science 153, 136-141 (1966).

5. C. B. Farmer, D. W. Davies, A. L. Holland, D. D. LaPorte, and P. E. Doms, "Mars: water vapor observations from the Viking orbiters,” J. Geophys. Res. 82, 4225-4248 (1977).

6. B. M. Jakosky and C. B. Farmer, "The seasonal and global behavior of water vapor in the Mars atmosphere: complete global results of the Viking Mars atmospheric water vapor experiment," J. Geophys. Res. 87, 2999-3019 (1982).

7. S. L. Hess, J. A. Ryan, J. E. Tillman, R. M. Henry, and C. B. Leovy, "The annual cycle of pressure on Mars measured by the Viking Landers 1 and 2," Geophys. Res. Lett. 7, 197-200 (1980).

8. B. Conrath, R. Curran, R. Hanel, V. Junde, W. Maguire, J. Pearl, J. Pirraglia, J. Walker, and T. Burke, "Atmospheric and 
surface properties of Mars obtained by infrared spectroscopy on Mariner 9,” J. Geophys. Res. 78, 4267-4278 (1973).

9. B. J. Conrath, "Planetary-scale wave structure in the Martian atmosphere," Icarus 48, 246-255 (1981).

10. J. B. Pollack, C. B. Leovy, P. W. Grieman, and Y. Mintz, "A Martian general circulation experiment with large topograph," J. Atmos. Sci. 38, 3-29 (1981).

11. D. McCleese, "Remote sensing of the atmosphere of Mars using IR-pressure modulation and filter radiometry," Appl. Opt. 25, 4232-4245 (1986).

12. C. A. Barth, C. W. Hord, A. I. Stewart, A. L. Lane, M. L. Dick, and G. P. Anderson, "Mariner 9 ultraviolet spectrometer experiment: seasonal variation of ozone on Mars," Science 179, 795-796 (1973).

13. D. M. Hunten, "Aeronomy of the lower atmosphere of Mars," Rev. Geophys. Space Phys. 12, 529-535 (1974).

14. E. S. Barker, "Martian atmospheric water vapor observations: 1972-74 apparitions," Icarus 28, 247-268 (1976).

15. D. W. Davies, "The Mars water cycle," Icarus 45, 398-414 (1981).

16. C. B. Farmer and P. E. Doms, "Global seasonal variation of water vapor on Mars and the implications for permafrost," J. Geophys. Res. 84, 2881-2888 (1979).

17. B. M. Jakosky and E. S. Barker, "Comparison of ground-based and Viking Orbiter measurements of Martian water vapor: variability of the seasonal cycle," Icarus 57, 322-334 (1984).

18. B. M. Jakosky, "The seasonal cycle of water on Mars," Space Sci. Rev. (to be published).

19. D. W. Davies, "The vertical distribution of Mars water vapor," J. Geophys. Res. 84, 2875-2880 (1979).
20. J. B. Pollack, D. Colburn, R. Kahn, J. Hunter, W. van Camp, C. E. Carleton, and M. R. Wolfe, "Properties of aerosols in the Martian atmosphere, as inferred from Viking Lander imaging data,” J. Geophys. Res. 82, 4479-4496 (1977).

21. F. M. Flasar and R. M. Goody, "Diurnal behavior of water on Mars,” Planet. Space Sci. 24, 161-181 (1976).

22. T. D. Parkinson and D. M. Hunten, "Spectroscopy and aeronomy of $\mathrm{O}_{2}$ on Mars," J. Atmos. Sci. 29, 1380-1390 (1972).

23. T. Y. Kong and M. B. McElroy, "Photochemistry of the Martian atmosphere," Icarus 32, 168-169 (1977).

24. J. F. Noxon, W. A. Traub, N. P. Carleton, and P. Connes, "Detection of $\mathrm{O}_{2}$ dayglow emission from Mars and the Martian ozone abundances,” Astrophys. J. 207, 1025-1035 (1986).

25. E. S. Barker, "Detection of molecular oxygen in the Martian atmosphere," Nature (Lett.) 238, 447-448 (1972).

26. N. P. Carleton and W. A. Traub, "Detection of molecular oxygen on Mars," Science 177, 988-992 (1972).

27. J. T. Trauger and J. I. Lunine, "Spectroscopy of molecular oxygen in the atmosphere of Venus and Mars," Icarus 55, 272-231 (1983).

28. C. Leovy and Y. Mintz, "Numerical simulation of the atmospheric circulation and climate of Mars," J. Atmos. Sci. 26, 1167-1190 (1969).

29. R. M. Haberle, C. B. Leovy, and J. B. Pollack, "A numerical model for the Martian polar cap winds," Icarus 39, 151-183 (1979).

30. P. Goldsmith, Department of Astronomy, Cornell University, Ithica, N.Y. 14583 (personal communication, January 1993). 